\title{
EDITORIAL
}

\section{Cost awareness and moral consciousness}

A seminal article by Kenneth Arrow (1963) is often credited with giving rise to health economics as a discipline. Other scholars quickly caught on. Three years later Victor Fuchs, for example, hired a young research assistant at the National Bureau of Economic Research, who subsequently graduated from Columbia University in 1970. In his doctoral studies the student focused on health as an economic phenomenon, under the guidance of Gary Becker. This person was Michael Grossman who published a central part of his doctoral thesis in the Journal of Political Economy (Grossman 1972), which helped focus the concept of health as human capital. That article marked a turn for the discipline of health economic. Michael Grossman is a contributor to the current issue.

Not long after his first publication, or in the early 1970s, interest in health economics started building within the Nordic countries. In the following years a few articles were published and the first individuals started graduating with doctoral theses that focused on health-economic topics. The Nordic Health Economic Study Group started in 1979 and held its first meeting in 1980 (Christiansen 2014).

People working in this field today still encounter questions on weather using the terms "health" and "economics" in one sentence, let alone to merge them into one term, "health economics" is appropriate or even ethically justifiable. Some of us can only imagine how foreign the concept must have been to people half a century ago when Kenneth Arrow was first working on health-related problems or in the following years when Michael Grossman started doing the same. Although the discipline has come far, this is still a complicated question to many, not least in the Nordic countries where health care is considered to be a right and thus high on the agenda in the public sphere.

The health systems of the Nordic countries are largely funded through taxation. The costs associated with population aging and other increased pressures on public finances are a concern. Cuts and savings are often mentioned as the necessary measures to relieve strain on governments. The question is whether to build on the concept of efficiency when tackling the problem. In order to address these concerns people need to understand what this kind of efficiency would involve?

To make a long story short, it means that health care should not only be effective; it also means that we should demand as much life and health as possible, in turn for the sacrifices we make for said health production. That, for example, involves picking and choosing within the health-care system. The fact remains that there are also other phenomena that give us well-being and pleasure, besides health. Therefore, it can be justified to limit public health production on the basis of some other wants or needs that we would like to fulfill. But within the health-care system, we would have to find a way to determine what health care we provide, and where the boundaries should lie between health and other desiderata that may increase our wellbeing.

I regularly hear two different views in debates on health care. They can, with some generalization, be summed up by the following statements:

(a) "It is incredible how we are constantly discussing the cost of health care. No one, however, speaks of the benefits! How valuable is this service to us? Life and health cannot be evaluated in monetary terms." 
(b) "It is unbelievable how people within the health sector think. It is a utopia to think that you can provide everyone with everything they need. Do those people think that the treasury is a bottomless pot of gold?"

It is sad how seldom those contrasting ideas - a focus on costs and a focus on benefits - are merged. That is the key. The benefits, that some people place so much emphasis on, need to be held up against the sacrifices that are a concern to others. This needs to be done in a systematic way. The task for decision makers in health care is thus in many ways to merge the two mentioned views. That is where efficiency becomes a key concept.

If the goal is to produce as much health as possible, we can do it in multiple ways. How much does each purchased unit of health cost if obtained by shoveling snow on the steps of the elderly every time it snows? What about inserting railing or crash barriers on more roads? Or more traffic lights? Should we vaccinate against chicken pox? What about kidney transplants for those over the age of 80? The health-producing possibilities are abundant and we need to keep in mind that many of them are not to be found within the formal health-care system. In fact, many of the main determinants of health involve individual lifestyle choices or the built environment around us. Some of the factors that have the greatest correlations with health are difficult to pin down as definite causes of health. This is, for example, the case with education, as discussed by Michael Grossman in his contribution to this issue. We need to know how weighty the health production aspect of education is in order to evaluate funding on education relative to other health producing possibilities.

You can answer many questions similar to the ones above on snow shoveling, railings and vaccinations with the help of common sense - others not. When the evaluation of interventions becomes a bit more difficult to gauge, your can do so with the help of health economics. The core aspect is that such evaluations should be done simultaneously with consideration of both views expressed above. That is (a) benefits and (b) costs should both be taken into account. The important part is that maybe as both statements above show, those considerations have limited meaning separately. However, those concerns become meaningful when considered in relation to each other. The point is that we have ways to evaluate what approaches to producing health provide the greatest effects relative to the sacrifices made. When this is done, then one can achieve both efficiency and fairness of a certain kind. If evaluating health-production according to efficiency criteria, the point lies, in my opinion, in optimizing health without favoring additional health for one person over another. Equality in the amount we are willing to pay for health, may not be the only moral compass that one would like to use, but it can certainly be an ethical stance. If wanting to deviate from this ethical standpoint, and argue that producing health for one person is so important to you that you are willing to forego a greater amount of health for others, you might want to at least know why and how large the net loss of health for society is. This is why cost awareness is a form of moral consciousness.

\section{Tinna Laufey Ásgeirsdóttir}

\section{References}

Arrow, Kenneth (1963) "Uncertainty and the welfare economics of medical care" The American Economic Review 53 (5), p. 941-73.

Christiansen, Terkel (2014) 'Editorial: The Nordic Health Economists' Study group (NHESG) 35 years" The Nordic Journal of Health Economics 2(1), p. 5-9.

Grossman, Michael (1972) "On the Concept of Health Capital and the Demand for Health" Journal of Political Economy 80 (2), p. 223-255. 